tät Berlin, derzeitiger Forschungsschwerpunkt: Feministische Medienöffentlichkeit, sonstige Arbeitsfelder: Kulturorganisation und -politik, Frauen in Kultur- und Kommunalpolitik.

Karin Werner, geb. 1960 in Halle/Westf, Studium der Soziologie und Geschichtswissenschaft in Bielefeld. Seit $1984 \mathrm{Be}$ schäftigung mit dem Nahen und Mittleren Osten, 1986 Diplomarbeit über die Auswirkungen der Weltmarktintegration Ägyptens auf Haushalte in Altkairo, 1986-91 Managementtätigkeit in einem Softwarehaus. 1991-1994 Stipendium im Graduiertenkolleg »Markt, Staat und Ethnizität« am Forschungsschwerpunkt Entwicklungsplanung der Fakultät für Soziologie an der Universität Bielefeld. 1995 Promotion. Seitdem Postdoktorandenstipendium in der Phase zwei des Graduiertenkollegs.

\section{Die nächsten Hefte}

In Planung sind folgende Themen

- Neue Medien

- 1968 revisited

- Mädchen: gestern - heute - morgen

Beiträge sind erwünscht.
Jolande Withuis, geb. 1949, studierte Soziologie an der Universität Amsterdam. Sie schreibt für die liberale Tageszeitung NRC Handelsblad und für die feministische Monatszeitschrift Opzij. Seit 1981 Lehre im Bereich von Frauenstudien an verschiedenen Universitäten, gegenwärtig mit einem Forschungsprojekt an der Katholischen Universität Nijmegen. Ihre Dissertation Opoffering en heroïek. De mentale wereld van een communistische Vrouwenorganisatie in naorlogs Nederland. 1946-1976 (1990) bekam den Preis der Nederlandse Kring voor Wetenschap der Politiek. Zuletzt erschien De jurk van de kosmonaute. Over politiek, cultuur en psyche (1995), eine Essaysammlung zu Geschlechterfragen im Zusammenhang mit der Verarbeitung des Zweiten Weltkriegs, mit dem Kommunismus, dem kalten Krieg und dem Feminismus in den Niederlanden. 